\title{
Canada owes refugees adequate health coverage
}

\author{
Matthew B. Stanbrook MD PhD
}

$\mathrm{R}$ efugees arriving in Canada have long received health coverage broadly similar to that available to Canadians receiving social assistance. This changed dramatically in mid-2012, when the federal government enacted substantial cuts to the Interim Federal Health Program. These cuts reduced access to health care for most refugees; some lost all health coverage except for treatment of conditions deemed a threat to public health or safety.

The cuts prompted widespread objections and warnings about adverse consequences from health professionals and others nationwide, which went unheeded. A recent study provides alarming evidence that these consequences have indeed come to pass. ${ }^{1}$ This report was based on data provided by clinicians across Canada using an online reporting tool. Although this report has the usual limitations of such surveys, including uncertainty about how systematic or representative the findings are, it provides important documentation of sentinel events in a manner analogous to our system for reporting of adverse drug effects. The author of the report, and the health professionals who contributed to it, should be commended for their efforts, especially because there is no evidence that the government has sought to evaluate the impact of its legislation.

This new evidence suggests that the cuts to health coverage have, in particular, denied refugees access to primary and preventive care. In addition to being medically irrational and essentially unfair, these cuts are economically irresponsible, because refugees are presenting to emergency departments with acute conditions that could have been prevented or treated in primary care at an earlier stage and at a lower cost. In particular, refugees have lost access to medications needed to control chronic diseases, such as inhalers for asthma (the commonest chronic disease among children), which has led to progression or exacerbation of those diseases. Even though treatment for a select list of public health conditions remains covered, the testing needed to diagnose these conditions often isn't, paradoxically. This results in a failure to protect either the public or the patient. Moreover, cuts appear to have disproportionately affected women, particularly through denial of prenatal care. Any resulting adverse consequences of this will be suffered primarily by babies who, upon their birth, will be Canadian citizens. Through it all, the changes have created such confusion and bureaucracy that coverage has often been denied erroneously to refugees who do qualify for it.

Rather than addressing the problems that have arisen from the changes, the federal government has failed to accept responsibility, choosing instead a defensive posture. Members of Parliament (MPs) have described the old coverage for refugees as "gold-plated" health care and have characterized critics of the changes as left-leaning activists, ${ }^{2}$ despite the fact that the critics represent virtually every medical organization in Canada (including the Canadian Medical Association). As justification for their policy, MPs have repeatedly put forward the need to address migrants with false claims to refugee status.

At stake here is not merely the up-front cost of refugee care, but also the decency of Canada's humanitarianism. The tone of the government's response paints refugees as aliens who are to be treated with suspicion, not as guests in our country deserving hospitality and needing help, and certainly not as citizens in waiting. Yet, considering that nearly $40 \%$ of refugees will become Canadian citizens, ${ }^{2}$ what we spend on them initially can be seen as an investment in the health of future Canadians who will go on to contribute to our economy and the growth of our country. They deserve to be valued accordingly. The problem posed by a minority of claimants who may be bogus will not be solved by taking away health coverage from refugees generally.

Most Canadians would not consider depriving sick children or pregnant women of health care, or anyone else in need for that matter, as consistent with our values, nor would we likely characterize adequate and necessary health care coverage as an unaffordable luxury, which seems to be the government's perspective. Instead, most Canadians consider universal health care a right deeply ingrained in our culture. A federal court challenge is underway claiming that the cuts are unconstitutional and violate Canada's international treaty obligations to be nondiscriminatory in the provision of health services. ${ }^{3}$

Although the federal government claims that the changes are saving \$20 million annually, they appear to have downloaded to the provinces even greater costs of treating health problems resulting from the cuts. ${ }^{4}$ Fortunately, provincial governments are now pushing back: most of Canada's provinces have pledged, effective January 2014, to restore most of the health coverage that was cut and to send the bill for this to Ottawa. ${ }^{4}$ Faced with this reality, Canada's new minister of health, Rona Ambrose, who has been essentially silent to date on the issue of refugee health, should do the right thing: own up to the consequences of the cuts and take steps to reverse them. This would be the sensible approach medically and economically. And it is the decent thing to do.

For references, see Appendix 1, available at www.cmaj.ca/lookup/suppl/doi :10.1503/cmaj.131861/-/DC1.

Competing interests: See www.cmaj.ca/site/misc/cmaj_staff.xhtml

Affiliation: Matthew Stanbrook is Deputy Editor, CMAJ.

Correspondence to: $C M A J$ editor, pubs@cmaj.ca

CMAJ 2014. DOI:10.1503/cmaj.131861 